
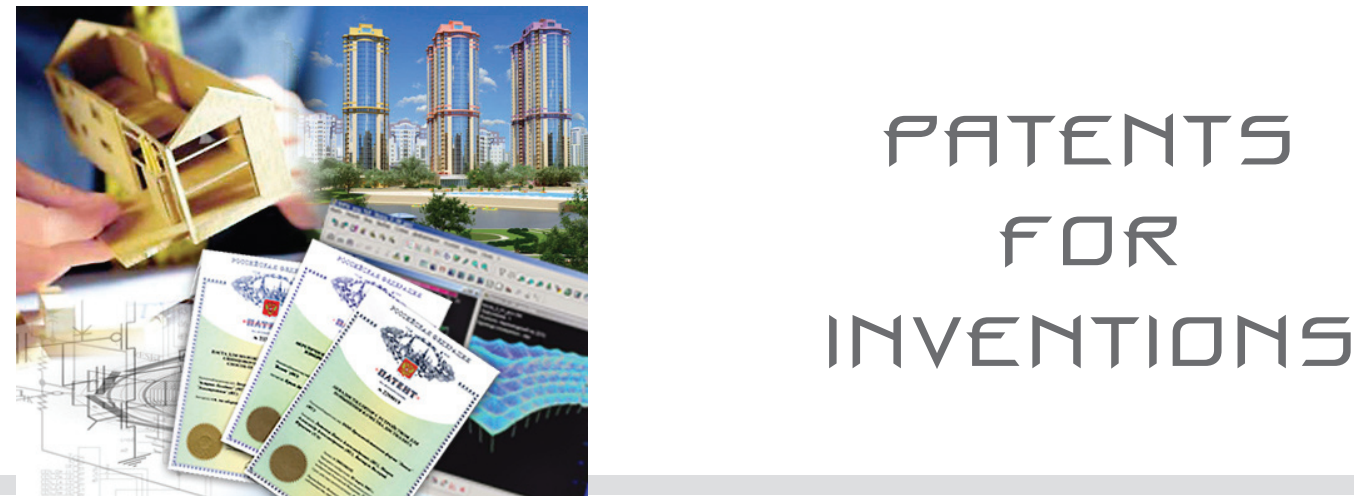

UDC 608; 69.001.5

VLASOV Vladimir Alexeevich, Ph.D. in Engineering, Expert, International Academy of Engineering;

Gazetny per., block 9, bld.4, Moscow, 125009, Russian Federation, e-mail: info@nanobuild.ru

\title{
THE REVIEW OF PATENTS IN THE AREA OF NANOTECHNOLOGIES AND NANOMATERIALS.
}

PART 1

The inventions in the area of nanotechnologies and nanomaterials produce a profound effect in construction, housing and communal services and adjacent economic fields. The invention «The method of production of mixture for composite honeycomb concrete (RU 2543847)» refers to the field of construction materials and can be used to produce non-autoclave composite honeycomb concrete of the natural hardening. This method consists of the following stages: supply of composition elements into mixer, mixing of the elements to obtain homogenous mass, introduction of dry cellulating mixture into obtained composition and further joint mixing; then obtained composition is provided with zeolite additive which is produced by means of preliminary mixing of one- or multilayer nanotubes in water with atomizer in sprayed form with further mixing with zeolite in the cyclic action mixer, the preliminary prepared dry cellulating mixture is also added. The technical result is a production of homogenous dry mixture, decrease of volume weight, increase of strength and frost resistance of non-autoclave honeycomb concrete manufactured from the specified dry mixture.

The invention "Nanostructured wood and mineral composite material (RU 2542025)» refers to the production of construction materials and can be used in manufacture of wood and mineral slabs and finishing materials in civil and in- 
dustrial engineering. The technical result is increased strength and water-resistance.

The specialists may be also interested in the following nanotechnological inventions: epoxy composition for high-strength, alcali-resistant structures (RU 2536141); nanocomposite material based on mineral binders (RU 2538410); the method to produce nanopowders of zinc oxide with surface modification for the use in building sealing material (RU 2505379); a composition for conglutination of metal products (RU 2526991); the method for production of nanodispersed powders (RU 2537678); the method of synthesis of micro- and nanocomposite aluminium and carbon materials (RU 2537623); the production method for films of amorphous silica containing nanocrystal inclusions (RU 2536775); the method of ultrasound finishing treatment for details made of structural and tool steel and a device to perform it (RU 2530678); nanostructured welding wire (RU 2538228).

Key words: nanocomposite material based on mineral binders, nanostructured wood and mineral composite material, production of composite honeycomb concrete, nanostructured welding wire.

\section{The method of production of mixture for composite honeycomb concrete (RU 2543847)}

The invention refers to the field of construction materials and can be used to produce non-autoclave composite honeycomb concrete of natural hardening [1]. This method consists of the following stages: supply of composition elements into mixer, mixing of the elements to obtain homogenous mass, introduction of dry cellulating mixture into obtained composition and further joint mixing; then obtained composition is provided with zeolite additive which is produced by means of preliminary mixing of one- or multilayer nanotubes in water with atomizer in sprayed form with further mixing with zeolite in the cyclic action mixer, than the preliminary prepared dry cellulating mixture (consists of foam former, aluminium powder PAP-2 and aluminium powder PAP-1) is added. After that the components of the dry mixture are supplied into the mixer following the ratio, kg.: cement -600 , fly ash TEZ -400 , microsilica MKY - 50, super plasticizer $\mathrm{C}-3-9$, natrium oleate -3 , natrium gluconate $-1,5$, adiment 
CT-2 -2 , biocide additive Lastonoks -2 , fiber $-1,5$, polymer additive 5 , mentioned dry cellulating mixture -20 , mentioned ceolite additive containing mono- or multilayer nanotubes, 50. Joint mixing results in a common composition which is exposed to mechanical activation in special plants. The technical result is a production of homogenous dry mixture, decrease of volume weight, increase of strength and frost resistance of non-autoclave honeycomb concrete manufactured from the specified dry mixture.

\section{Diamond coating and the method to produce it (RU 2544219)}

The invention refers to nanotechnology, in particularly to the diamond nanocrystal coatings and the methods to produce it with the use of nanodiamonds [2]. The diamond coating consists of underlayer with nanodiamond particles which size is $2-30 \mathrm{~nm}$ and diamond layer which is applied by means of sedimentation of the gas. The underlayer is made of composite material which possesses metal or non-metalbinder and mentioned above nanodiamond particles with inclusion volume fraction 5-90\%. The method to produce diamond coating on the base plate includes two stages: application of underlayer containing nanodiamond particles which size is 2-30 nm; application of diamond layer by means of sedimentation of the gas. The underlayer with nanodiamond particles is made of composite materials which possesses metal or non-metal binder and mentioned above nanodiamond particles with inclusion volume fraction $5-90 \%$.

\section{High-strength carbon material and the method to produce it (RU 2543891)}

The invention is designed for aerospace and defense industries, as well as for the treatment of hard and super hard materials [3]. Molecular fullerene $\mathrm{C}_{60}$ or fullerene-containing soot with additive of sulfur-containing compound is exposed to the pressure 0,2-12 $\mathrm{GPa}$ and temperature from 0 to $2000^{\circ} \mathrm{C}$. Carbon disulfide, compound from the group of mercaptans or the product of interaction between simple sulfur and the mercaptan compound, can be used as sulfur-containing compound. The structure of the obtained high-strength carbon material is formed by layers binded by 
covalent bonds of two-dimension polarized along rotation axis of the second degree fullerene molecules. The hardness of the produced material is more $10 \mathrm{GPa}$.

\section{The cobalt based alloy for application of coatings (RU 2543579)}

The invention refers to metallurgy of alloys based on cobalt and designed for production of wear-resistant coatings with high micro-hardness obtained by means of the heterophasis transfer methods [4]. The composition of the alloy based on cobalt is the following, mas. $\%: 20,0-30,0 \mathrm{Cr} ; 6,0-12,0 \mathrm{Si}$; $2,0-4,0 \mathrm{~B} ; 0,2-0,8 \mathrm{Y} ; 0,1-0,6 \mathrm{Ce} ; 0,3-0,9 \mathrm{La}$. The ratio of silica to boron is $3: 1$ and the structure of the alloy is a metal matrix with nanosize particles of oxides Ce which size is $30-80 \mathrm{~nm}$, nitrides $\mathrm{Y}$ which size is $50-100 \mathrm{~nm}$ and hydrides La which size is $20-60 \mathrm{~nm}$. The inclusion volume fraction of nanosize particles in alloy is $30-50 \%$. The proposed alloy for application of coatings provides increased wear-resistance of coatings due to rise of micro-hardness to $68-72$ HRc.

\section{Nanofiber polymer material (RU 2543377)}

The invention refers to nonwoven polymer nanofiber materials based on polyhydroxybutyrate used to filter different media [5]. Nonwoven polymer nanofiber is produced from molding solution based on polyhydroxybutyrate, which contents nanocrystal silica in the quantity of $0,1-1,5$ mas. $\%$, and technological additive which is salt of tetrabutylammonia iodide dissolved in the mixture of chloroform and formic acid with concentration $1 \mathrm{~g} / \mathrm{l}$. The obtained polymer nonwoven composite material possesses increased durability and resistance to UV-radiation.

\section{Dry glues}

(RU 2543188)

Dry glue includes microstructure and nanostructural surface and elastic surface which hardness by Shore A is about 60 or less [6]. At that microstructural and nanostructural surfaces and elastic surface can form 
dry glue adhesive assembly when contacting each other through convertible mechanical interlock of elastic surface in micropores and nanopores. The technical result of the use of the glue is increased dry adhesion and the thicker elastic surface.

\section{The method to produce composite material (RU 2543030)}

The invention refers to the methods for production of composite nanomaterials and can be used in device engineering and other industries for manufacture of materials based on semiconductors, dielectric and metals [7]. The method consists of the following stages: vacuum precipitation on base plate of monocrystal silica with orientation of cutoff (111) or (001) of films of transition metals $\mathrm{Co}$, Fe or $\mathrm{Cr}$ which thickness is divisible by one fourth or length of the wave of their electrons; formation of structurally uneven subelements in one boundary area between the film and base plate within the thicknesses of layers which are equal at least to three monolayers. The sizes of the subelements, at least in one direction, are divisible by period of the lattice and/or one fourth of length of the wave of valence electrons of material of the layer or plate. The application of the invention allows producing composite nanomaterials with new or improved consumer properties due to formation of uneven nanostructural state in composite nanomaterial.

\section{Automated technological line for surface modification with metal-oxide nanoparticles of polymer fiber material (RU 2542303)}

Automated technological line for surface modification with metaloxide nanoparticles of polymer fiber material can be used in production of filter material designed for refinement of water from organic wastes [8]. The automated line comprises subsequently set hydrolysis block, containerstorage of polymer fiber material, SHF block, block of ultrasound washing and the block of drying modified polymer fiber material. The polymer fiber material is moved by line-drive mechanism. The line-drive mechanism consists of pinch rollers installed at the entry and exit of all blocks and guide rollers set inside of each block. The container-storage is used to 
synchronize the rate of moving of polymer fiber material from reservoir with metal salt solution (in hydrolysis block) to SHF block. Magnetrons in SHF block are parallel to the movement line of polymer fiber material and are installed in such a way to provide interchange of maximums and minimums of electromagnetic fields by half-length of the wave. There are quarter-wave absorbing traps at the entry and exit of SHF block. The block of ultrasound washing consists of reservoir of stainless steel for washing liquid and electronic ultrasound generator connected with ultrasound converter set in reservoir body. The blocks of drying modified polymer fiber materials is performed in the form of hermetic container, there are rows of infrared lamps inside of it, and it is equipped with air-exhauster. The operation of the automated technological line is performed by means of the block of automated control. The invention makes it possible to provide synchronized work of all blocks, continuous process of production of filtered material and even distribution of metaloxide nanoparticles on the surface of polymer fiber material.

\section{The method to produce ultradispersed powder of montmorillonite (RU 2542257)}

The invention refers to the production of composite polymer materials, technology of increasing performance characteristics of polymers with the use of dispersed fillers [9]. The method of production of montmorillonite powder includes the following stages: montmorillonite is treated in activators of planetary type $А \Pi \Phi-3$ at least for 500 minutes and then the powder is dried under $120^{\circ} \mathrm{C}$ for 60 minutes. The obtained nanosize montmorillonite is characterized by activated surface which is favour for increased filler adhesion to polymer matrix and as a result improve of operational properties of modified material.

\section{The method of production of nanostructured coating (RU 2542218)}

The invention refers to the method of production of nanostructured coating to protect article surface [10]. The method consists of the following stages: formation of high-temperature gas flow in spray combustion chamber due to fuel burning in oxidant; supply of initial material which 
is the source of nanoparticles formation into combustion chamber; formation and transportation of nanoparticles by high-temperature gas flow and precipitation of them on base plate. At that the initial material is transformed into gas state due to impact of high-temperature gas flow in combustion chamber. Then gas flow when left the combustion chamber is cooled rapidly to the temperature which is lower than melting temperature of initial material. The cooling of gas flow can be performed by mixing it with cold flow of inert gas. The technical result is that nanostructured coatings of high quality are produced with the use of powder materials of metallurgy industry.

\section{The plant for treatment of nanocomposites in hydrogen plasma (RU 2542211)}

The invention refers to vacuum-plasma treatment of composites. The plant for treatment of nanocomposites in hydrogen plasma consists of SHF oven and oven quartz reactor (installed inside of SHF) to dispose composites. The reactor is the body in form of hollow cylinder of quartz glass and dielectric collets with termination points set on the flanks of the cylinder by means of vacuum compaction. The termination points are necessary to connect dielectric collets with vacuum hoses, one of which supplies hydrogen and possesses inlet valve and another one provides pumpdown of SHF oven and reactor by means of mechanical pump. Each of termination points is a compound and comprises an outer shell, a cap, a filler and shaped cushion made of quartz glass with central hole. The outer shell is made in the form of hollow two-stage cylinder with termination point for vacuum hose and possesses outer screw thread for cap installation and inner cone surface to install filler in cone gap between reactor body and outer shell. The cap is placed between flank of the outer shell and the flank of reactor body. That provides continuous treatment of nanocomposites [11].

\section{The method to produce nonshrinking nanomodified constructional ceramic material (RU 2542073)}

The invention refers to constructional materials [12]. The technical result of the invention is that it provides increased dimensional stability, 
high-temperature strength and heat fastness, keeps mechanical durability within the temperature range $25-1400^{\circ} \mathrm{C}$, increases durability and phase stability in any mode of the use of material within the mentioned temperature range. At first the preliminary plansifter of initial raw materials which includes silicon carbide, boron nitride and aluminium is performed, then batch is made of it, then grinding, mechanical activation and drying are carried out. Aluminium is taken in the form of ultradispersed powder with average particle size $4 \mu \mathrm{m}$, containing $3-10 \%$ mas. $\%$ of aluminium nanoparticles which size is $100-300 \mathrm{~nm}$. The mechanical activation is performed under acceleration $9-10 \mathrm{~g}$. Vacuum baking is carried out within the temperature range $1150-1250^{\circ} \mathrm{C}$ with residual pressure $0,05 \mathrm{~atm}$. and further high-temperature burning at open air at least for 100 hours under the temperature $1200-1300^{\circ} \mathrm{C}$.

\section{Nanostructured wood and mineral composite material (RU 2542025)}

The invention refers to production of construction materials and can be used in manufacture of wood and mineral slabs and finishing materials in civil and industrial engineering. The technical result is increased strength and water-resistance. Nanostructured wood and mineral composite material contains wood filled, binder, water and additionally contains reinforcing filler of basalt with average particle size $50-100 \mathrm{~nm}$. Wood filler is softwood in the form of microdispersed particles with the average size 1-2 $\mu \mathrm{m}$ and the following ratio of the components, mas. $\%$ : wood $-40-55$, basalt $-30-$ 40 , slack lime $-10-15$, water is the rest [13].

\section{Precise sensor of pressure based on nano- and microelectromechanical system (RU 2541714)}

The invention refers to instrumentation and can be used to measure pressure of liquid and gas substances [14]. The nano- and microelectromechanical system (NaMEMS) is installed on the sensor's body. NaMEMS consists of elastic element - membrane with hard center, with peripheral base in the form of rotational shell, on which there is heterogenous structure of thin films of materials and in which contact areas, 
the first radial resistive-strain sensors and the second radial resistive-strain sensors are formed. The first radial resistive-strain sensors made of the equal resistive-strain elements located by membrane circle and the second radial resistive-strain sensors made of the equal resistive-strain elements located on another circle of the membrane are connected by bridles and switched on bridge. The radius of the hard center is determined by the ratio: $\mathrm{r}_{\text {h.c. }}=0,42 \mathrm{r}_{\mathrm{m}}$, где $\mathrm{r}_{\mathrm{m}}$ - radius of the membrane. At that resistive-strain elements of the first radial resistive-strain sensors are arranged along the circe which radius is determined according to the ratio $r_{1}=0,444 \mathrm{r}_{\mathrm{m}}$, and resistive-strain elements of the second radial resistive-strain sensors are arranged along the circe which radius is determined according to the ratio $\mathrm{r}_{2}=0,733 \mathrm{r}_{\mathrm{m}}$. The technical result of the invention is increased accuracy due to increased sensibility at simultaneous decrease of nonlinearity.

\section{High-resource electric-arc generator of low temperature plasma with protective nanostructured carbon coating of electrodes (RU 2541349)}

The invention refers to transformation of electric power into thermal power by means of voltaic arc in generator of low temperature plasma (plasmatron) and can be used in power engineering to ignite and light coalfired torch in furnace chambers, in metallurgy and chemical industry to produce ultradispersed smut which is a raw material for nanostructures technical carbon. Plasmatron contains outer electrode, axially aligned inner electrode-cathodeholder, swirl chamber for supply of plasmaformating gas. Electrodes are isolated and arranged in induction coils. Inner electrodecathodeholder is hollow. Carbonhydrates of methan row are supplied into arc channel of the outer electrode through outlet channels and circle cavity. Hydrocarbons of methan row getintocathodearea through the tube arranged along the axis of the inner electrode-cathodeholder and cavity formed by position of the cathode in hollow electrode-cathodeholder. Plasmotron possesses at least four channels to supply hydrocarbon gas in cathode area of voltaic arc. The channels are distributed evenly along the circle. Supply of hydrocarbon gas into cathode area of voltaic arc is performed in three options. The technical result of the invention is increased operation life span of the electrode due to stable renewal of protective carbon nanostructured layer [15]. 


\section{Nanostructured powder wire (RU 2538875)}

The invention can be used in arc welding and welding deposition of metal details. On the exterior and/or inner surface of metal shell of powder wire there is a nanocompositional coating in the form of metal matrix with the mixture of nanosize particles of metal fluoride and rare-earth metals distributed in it. Placed in the shell, batch contains slag-making, gas-producing, ionizing and finishing elements. The ratio between matrix volume and nanosize particles in given coating is, \%: metal matrix $-55-98$, nanosize particles of metal fluoride $-1-30$, nanosize particles of rare-earth metals - 1-15. Nanostructured powder wire possesses high welding and technological properties, provides small drop transfer of electrode metal and makes it possible to improve mechanical properties of welding joints [16].

The specialists may be also interested in the following nanotechnological inventions:

- Epoxy composition for high-strength, alcali-resistant structures (RU 2536141) [17].

- Nanocomposite material based on mineral binders (RU 2538410) [18].

- The method to produce nanopowders of zinc oxide with surface modification for the use in building sealing material (RU 2505379) [19].

- A composition for conglutination of metal products (RU 2526991) [20].

- The method for production of nanodispersed powders (RU 2537678) [21].

- the method of synthesis of micro- and nanocomposite aluminium and carbon materials (RU 2537623) [22].

- The production method for films of amorphous silica containing nanocrystal inclusions (RU 2536775) [23].

- The method of ultrasound finishing treatment for details made of structural and tool steel and a device to perform it (RU 2530678) [24].

- The method and device for material dispersion (RU 2536499) [25].

- $\quad$ Nanostructured welding wire (RU 2538228) [26]. 


\section{References:}

1. Patents and inventions registered in RF and USSR [Electronic source]. - Access mode: http://www.findpatent.ru/patent/254/2543847.html (date of access: 10.03.15).

2. Patents and inventions registered in RF and USSR [Electronic source]. - Access mode: http://www.findpatent.ru/patent/254/2544219.html (date of access: 10.03.15).

3. Patents and inventions registered in RF and USSR [Electronic source]. - Access mode: http://www.findpatent.ru/patent/254/2543891.html (date of access: 10.03.15).

4. Patents and inventions registered in RF and USSR [Electronic source]. - Access mode: http://www.findpatent.ru/patent/254/2543579.html (date of access: 10.03.15).

5. Patents and inventions registered in RF and USSR [Electronic source]. - Access mode: http://www.findpatent.ru/patent/254/2543377.html (date of access: 10.03.15).

6. Patents and inventions registered in RF and USSR [Electronic source]. - Access mode: http://www.findpatent.ru/patent/254/2543188.html (date of access: 10.03.15).

7. Patents and inventions registered in RF and USSR [Electronic source]. - Access mode: http://www.findpatent.ru/patent/254/2543030.html (date of access: 10.03.15).

8. Patents and inventions registered in RF and USSR [Electronic source]. - Access mode: http://www.findpatent.ru/patent/254/2542303.html (date of access: 10.03.15).

9. Patents and inventions registered in RF and USSR [Electronic source]. - Access mode: http://www.findpatent.ru/patent/254/2542257.html (date of access: 10.03.15).

10. Patents and inventions registered in RF and USSR [Electronic source]. - Access mode: http://www.findpatent.ru/patent/254/2542218.html (date of access: 10.03.15).

11. Patents and inventions registered in RF and USSR [Electronic source]. - Access mode: http://www.findpatent.ru/patent/254/2542211.html (date of access: 10.03.15).

12. Patents and inventions registered in RF and USSR [Electronic source]. - Access mode: http://www.findpatent.ru/patent/254/2542073.html (date of access: 10.03.15).

13. Patents and inventions registered in RF and USSR [Electronic source]. - Access mode: http://www.findpatent.ru/patent/254/2542025.html (date of access: 10.03.15).

14. Patents and inventions registered in RF and USSR [Electronic source]. - Access mode: http://www.findpatent.ru/patent/254/2541714.html (date of access: 10.03.15).

15. Patents and inventions registered in RF and USSR [Electronic source]. - Access mode: http://www.findpatent.ru/patent/254/2541349.html (date of access: 10.03.15).

16. Patents and inventions registered in RF and USSR [Electronic source]. - Access mode: http://www.findpatent.ru/patent/253/2538875.html (date of access: 10.03.15).

17. Vlasov V.A. Nanotechnological inventions and nanomaterials produce a profound effect in different areas of economy. Nanotehnologii v stroitel'stve = Nanotechnologies in Construction. 2015, Vol. 7, no. 1, pp. 82-104. DOI: dx.doi.org/10.15828/2075-8545-2015-71-82-104.

18. Patents and inventions registered in RF and USSR [Electronic source]. - Access mode: http://www.findpatent.ru/patent/253/2538410.html (date of access: 10.03.15). 
19. Vlasov V.A. Inventions in the nanotechnological area provide improved performance characteristics of different sealing polymer materials used in construction. Nanotehnologii v stroitel'stve $=$ Nanotechnologies in Construction. 2014, Vol. 6, no. 2, pp. 78-107. Available at: http://nanobuild.ru/en_EN/(date of access: 10.03.15). (In Russian).

20. Vlasov V.A. The inventions in nanotechnological area increase the efficiency of construction, housing and communal services and adjacent economic fields. Nanotehnologii v stroitel'stve $=$ Nanotechnologies in Construction. 2014, Vol. 6, no. 5, pp. 93-113. DOI:dx. doi.org/10.15828/2075-8545-2014-6-5-93-113. (In Russian).

21. Patents and inventions registered in RF and USSR [Electronic source]. - Access mode: http://www.findpatent.ru/patent/253/2537678.html (date of access: 10.03.15).

22. Patents and inventions registered in RF and USSR [Electronic source]. - Access mode: http://www.findpatent.ru/patent/253/2537623.html (date of access: 10.03.15).

23. Patents and inventions registered in RF and USSR [Electronic source]. - Access mode: http://www.findpatent.ru/patent/253/2536775.html (date of access: 10.03.15).

24. Vlasov V.A. The nanotechnological inventions raise competitive ability of the products. Nanotehnologii v stroitel'stve $=$ Nanotechnologies in Construction. 2014, Vol. 6, no. 6, pp. 58-78. DOI: dx.doi.org/10.15828/2075-8545-2014-6-6-58-78.

25. Patents and inventions registered in RF and USSR [Electronic source]. - Access mode: http://www.findpatent.ru/patent/253/2536499.html (date of access: 10.03.15).

26. Patents and inventions registered in RF and USSR [Electronic source]. - Access mode: http://www.findpatent.ru/patent/253/2538228.html (date of access: 10.03.15).

Dear Colleagues!

THE REFERENCE TO THIS PAPER HAS THE FOLLOWING CITATION FORMAT:

Vlasov V.A. The review of patents in the area of nanotechnologies and nanomaterials. Part 1. Nanotehnologii v stroitel'stve $=$ Nanotechnologies in Construction. 2015, Vol. 7, no. 2, pp. 89-114. DOI: dx.doi.org/10.15828/2075-8545-2015-7-289-114. 